\section{EXCESS SUGAR LINKED TO CANCER}

A recent discovery by scientists at the University Rey Juan Carlos in Madrid provides an explanation of how excess sugar can trigger cancer development. ${ }^{1}$

The scientists, led by Dr Custodia García-Jimenez, studied how the intestine responds to sugar. When sugar is ingested, cells in the intestine respond by releasing a hormone called GIP. This in turn increases insulin release from the pancreas, a hormone that controls blood sugar level. The release of GIP is dependent on a protein called $\beta$-catenin, and increased activity of $\beta$-catenin is associated with many forms of cancer. The research team demonstrated that high (but not normal) sugar levels trigger accumulation of $\beta$-catenin in the cell nucleus. In the nucleus, $\beta$-catenin can interact with other proteins to activate genes that trigger cell proliferation. This process can ultimately lead to cancer.

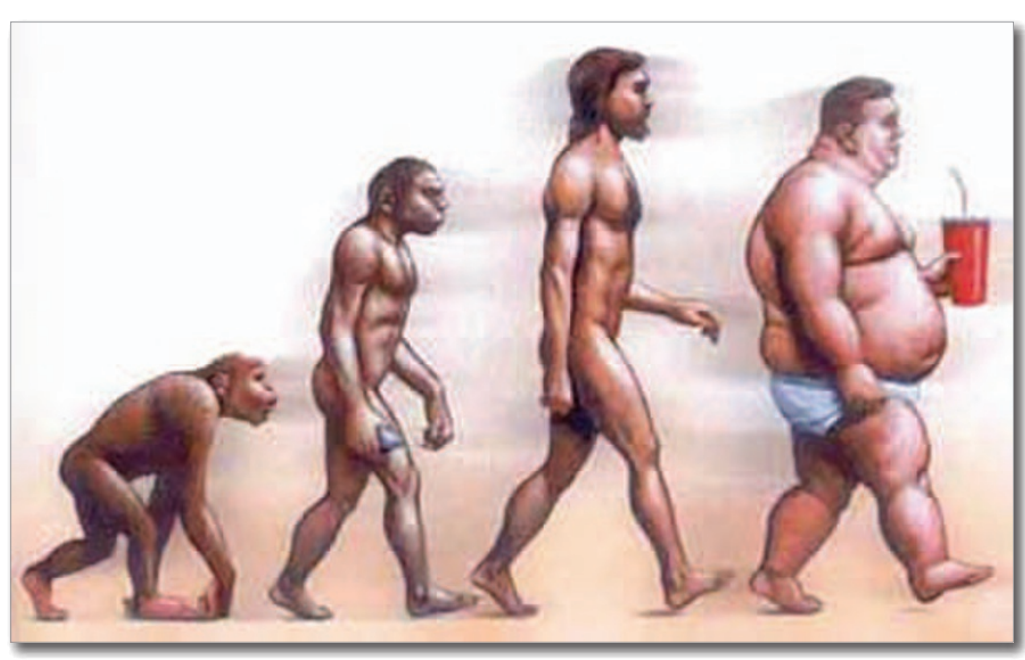
our metabolism caused by dietary sugar impact on our cancer risk. We are now investigating what other dietary components may influence our cancer risk. Changing diet is one of the easiest prevention strategies that can potentially save a lot of suffering and money'

The implications of these findings are vast. In 2011, the World Health Organisation named diabetes and cancer among the top ten causes of death in the developed world and one in ten adults suffer diabetes worldwide. These findings emphasise the importance of a healthy diet to prevent disease, and may also direct creation of novel therapies to combat cancer.

1. Chocarro-Calvo A, Garcia-Martinez J M, Ardila-González S, De la Vieja A, GarciaJimenez $C$. Glucose-induced $\beta$-catenin acetylation enhances Wnt signaling in cancer. Mol Cel/ 2012; doi: 10.1016/j. molcel.2012.11.022 [Epub ahead of print].

\section{By Anna Pouncey}

\section{HONOURS, AWARDS, APPOINTMENTS}

\section{BDA BULLETIN}

- Webpages designed to help dentists improve their practice through evidence-based information and to provide financial support for research where evidence is lacking are now available. The 'Curious about' webpages are from the Shirley Glasstone Hughes (SGH) Trust Fund. The launch of the webpages coincides with a call for applications to investigate the question: Do dental restorative materials containing plastics act as environmental pollutants? Research teams with a primary care dental practitioner are invited to apply for up to $£ 200,000$. Visit www.bda.org/curiousabout.

- The BDA has welcomed the approach of a United Nations treaty that aims to reduce mercury pollution. The treaty was agreed in January in Geneva at a meeting of the UN's Intergovernmental Negotiating Committee and will require nations to phase down the use of dental amalgam fillings over an appropriate time period.

\section{NEW CLINICS OPEN ON THE HIGH STREET}

Smileright Dental Clinics has opened two new dental clinics in branches of Boots, one in Old Basing Mall in Basingstoke, and the other at 197/199 High Street, Cheltenham.

With state-of-the-art facilities, the Smileright team of dentists, dental hygienists and dental nurses will provide a full range of affordable, high quality dental care located within the easily accessible high street setting of a Boots UK store.
Dr Charles Quail BDS, CEO of Smileright said: "At Smileright, our main focus is on improving and maintaining the oral health of the local community. We're delighted to be renting space within Boots UK stores as this allows us to provide affordable, convenient access to dental care.'

\section{GET TO GRIPS WITH ETHICAL DILEMMAS}

The Dental Defence Union (DDU) has produced an online learning module to help dental professionals get to grips with the ethical dilemmas they face in their day-to-day practice, with verifiable CPD.

The module aims to help members understand the main principles of topics such as confidentiality, consent and capacity. 